\title{
Formulasi Balsam Aromatherapy dari Ekstrak Minyak Atsiri Daun Sembung (Blumea balsamifera L.)
}

\author{
Formulation of Aromatherapy Balsam from Essential Oil \\ (Blumea balsamifera L.) \\ Hasrita Maghfirah $^{1}$, Saisa $^{2 *}$, Soraya Lestari $^{3}$, Rulia Meilina ${ }^{4}$ \\ ${ }^{1,3,4}$ Program Studi Farmasi Fakultas Ilmu Kesehatan Universitas Ubudiyah Indonesia, Jalan Alue Naga, Banda Aceh, \\ Indonesia \\ ${ }^{2}$ Program Studi Teknik Kimia Fakultas Teknik Universitas Serambi Mekkah, Batoh, Kecamatan Lueng Bata, Banda Aceh, \\ Indonesia \\ * Korespondensi Penulis: saisa@serambimekkah.ac.id
}

\begin{abstract}
Abstrak
Indonesia merupakan negara yang memiliki iklim tropis sehingga menyebabkan Indonesia memiliki sumber produksi dan sumber tumbuhnya tumbuhan yang berkhasiat sebagai obat seperti pada tanaman sembung (Blumea balsamifera L.). Pada tanaman ini ditemukan beberapa golongan senyawa kimia salah satunya ialah kandungan, minyak atsiri tidak hanya memiliki aroma yang khas tetapi minyak atsiri memiliki khasiat sebagai pengobatan. Penelitian ini bertujuan untuk mengetahui bagaimana proses pengolahan minyak atsiri dari daun sembung sebagai sediaan balsam aromatherapy. Penelitian ini bersifat deskriptif atau mengamati dan mendeskripsikan hasil yang diperoleh. Minyak atsiri daun sembung yang dihasilkan melalui proses pengeringan daun sembung serta menggunakan metode sokletasi dengan menggunakan pelarut $96 \%$ etanol, hasil ektrak kental kemudian dievaporasi untuk dipekatkan, hasil minyak atsiri daun sembung yang diperoleh berupa cairan berwarna hijau kehitaman. Sediaan balsam aromatherapy dari ekstrak minyak atsiridiformulasikan dengan beberapa konsentrasi yaitu $0 \%, 10 \%, 12 \%$ dan $14 \%$ dari hasil evaluasi balsam yang telah dilakukan ke 3 formula balsam memenuhi syarat dan memiliki mutu fisik yang baik. Uji kesukaan yang dilakukan terhadap 10 orang responden berdasarkan aroma, tekstur, dan warna yang disukai, sehingga diperoleh persentase tertinggi pada balsam ekstrak minyak atsirisembung dengan kode sampel D dan memiliki konsentrasi 14\% dengan tambahan 5,6 $\mathrm{mL}$ minyak daun sembung pada basis balsam.
\end{abstract}

Kata kunci: Sembung (Blumea balsamiferaL.), minyak atsiri, balsam aromatherapy

\begin{abstract}
Indonesia is a country that has a tropical climate that causes Indonesia to have a source of production and the source of the growth of plants as nutritious medicinal plants such as the sembung (Blumea balsamifera L.). In this plant found several classes of chemical compounds one of them is the content, atisiri oil not only has a distinctive aroma but essential oils have efficacy as a treatment. This study aims to find out how the processing of essential oil from the leaves of sembung as a preparation of aromatherapy balm. This research is descriptive or observes and describes the results obtained. The essential oil of the leafy leaves is produced through the process of drying the leaf of the leaves and using the method of sokletasi using $96 \%$ ethanol solvent, the result of thickened extract is then evaporated to concentrate, the result of the leaf of sacred leaf oil obtained by the liquid is blackish green. The preparation of
\end{abstract}


aromatherapy balm from essential oil extract is formulated with some concentrations of $0 \%$, $10 \%, 12 \%$ and $14 \%$ of the evaluation of balm which has been done to 3 qualified balm formulas and has good physical quality. Preferred tests of 10 respondent are based on preferred scents, textures, and colors, resulting in the highest percentage of a balee extract of essential oil of sembung with sample code D and has a concentration of $14 \%$ with an additional $5.6 \mathrm{~mL}$ of oil of leaf of sembung on base of balm.

Keywords: Sembung (Blumea balsamifera L.), Essential Oils, Aromatherapy balsam

\section{PENDAHULUAN}

Tanaman sembung (Blumea balsamifera L.) sudah tidak asing bagi masyarakat Indonesia khususnya didaerah yang berada dipesisir pantai maupun di daerah pegunungan. Kurangnya pengetahuan masyarakat tentang manfaat tumbuhan sembung ini menjadi alasan mengapa tumbuhan ini dibiarkan begitu saja dan tumbuh liar serta tidak dimanfaatkan, sedangkan tanaman sembung memiliki berbagai manfaat sebagai obat (Pilliang, 2011). Daun sembung rasanya pahit, namun sangatlah manjur untuk dijadikan obat tradisional terutama dalam bentuk jamu, dikarenakan cara pengolahan yang cukup sederhana menjadikan alasan dalam pemanfaatan sebagai obat tradisional, Komponen yang dominan dari minyak atsiri pada tanaman sembung (Blumea balsamifera L.) mengandungborneol, kamfer, sinelol, limonen, asam palmitik, asam miristik dan sesquiterpen alkohol pada analisis GC-MS menunjukkan bahwa minyak ini mengandung borneol (33,22\%), Karyopilen (8,24\%), ledol $(7,12 \%)$ dan fitol $(4,63 \%)$ (Pang et al, 2014). Tidak hanya karena aromanya yang khas daun sembung juga memiliki beberapa senyawa yang terkandung pada tanaman sembung salah satunya ialah minyak atsiri yang bermanfaat dalam pengobatan seperti anti nyeri, anti diare, penyakit lambung kronis, sakit kepala, nyeri haid, gatal-gatal, sesak nafas dan sebagainya (Piliang, 2011). Minyak atsiri daun sembung juga dapat dimanfaatkan sebagai aromatherapy pada sediaan balsam.

Mahalnya obat-obat sintetik modern, memberikan alternatif tersendiri bagi masyarakat untuk menggunakan tanaman yang sesuai pengalaman dan dapat digunakan untuk meningkatkan kesehatan, dengan menggunakan minyak atsiri yang digosokanlangsung maupun dalam bentuk produk seperti penggunaan cream ataupun balsam (Triratnawati, 2010). Balsam adalah sediaan yang tidak asing lagi khususnya masyarakat Indonesia dikarenakan balsam memiliki aromatherapy, serta memiliki rasa yang hangat saat digunakan. Balsam digunakan dengan cara menggosokan pada bagian kulit tubuh umumnya digunakan untuk meringankan sakit kepala, sakit perut, sakit gigi, menghilangkan gatal-gatal akibat gigitan 
serangga, pegal- pegal, pilek dan hidung tersumbat karena flu dan juga biasa digunakan untuk pijat. Balsam bertujuan untuk mengobati ataupun hanya sekedarmerelaksasikan walau dampak penyembuhan agak sedikit terlambat dibandingkan dengan mengonsumsi obat kimia secara langsung, akan tetapi efek samping dari penggunaan obat kimia saat ini juga sangat membahayakan bagi tubuh, oleh karena itu masyarakat terkadang menggunakan balsam sebagai suatu penyembuhan (Zulkarnain \& Aminullah, 2012).

Untuk mengekstrak minyak atsiri daun sembung dilakukan dengan menggunakan metode sokletasi dengan menggunakan pelarut. Metode ekstraksi sokletasimerupakan supatu metode dengan pemanasan, sokletasi sangat cocok digunakan dalam mengektrak minyak atsiri dikarenakan menggunakan panas yang stabil, dan menggunakan pelarut yang selalu baru, sehingga seluruh komponen senyawa minyak atsiri akan terekstrak dengan baik. Hasil ektrak minyak atsiri yang diperoleh kemudian akan diformulasikan menjadi sediaan balsam aromatherapy. Sediaan balsam sangat dipilih dikarenakan penggunaan yang sangat mudah dengan cara mengoleskan pada bagian kulit tubuh, Balsam dapat menghasilkan mutu fisik yang baik dan sesuai standar yang telah ditetapkan berdasarkan evaluasi-evaluasi terhadap balsam yaitu organoleptis (bentuk, warna, dan bau) dan uji homogenitas. Selain dilakukan evaluasi tersebut dilakukan uji kesukaan kepada 10 orang responden untuk mengetahui pendapat masyarakat mengenai mutu fisik dari balsam tersebut.

\section{METODE PENELITIAN}

Proses ekstraksi pada penelitian ini dilakukan dengan menggunakan metode sokletasi dengan menggunakan etanol $96 \%$ sebagai pelarut. Sokletasi ini dilakukan dengan cara daun sembung yang telah dikeringkan kemudian dihaluskan, serbuk simplisia kering kemudian ditimbang sebanyak 100 gr, kemudian dibungkus dengan kertas saring dan diikat kuat. Serbuk simplisia daun sembung dimasukaan kedalam alat sokletasi dengan pemanasan yang stabil, pemanasan dilakukan sesuai dengan suhu etanol kemudian ekstraksi dilakukan dalam waktu 2-8 jam sampai warna pelarut jernih. Hasil ekstrak kemudiadievaporasi untuk mendapatkan hasil minyak murni untuk diformulasikan sebagai sediaan balsam.

\section{Alat dan Bahan}

Alat yang akan digunakan dalam penelitian ini adalah : Pisau,masker, sarung tangan, timbangan, kertas saring, labu alas bulat, waterbath, termometer, pipet volume, corong, statif dan klem, seperangkat alat sokletasi, beker gelas, gelas ukur, pengaduk, kaca arloji, penangas 
air, tissu (serbet), wadah balsam, lumpang, kompor listrik, cawan porselin, kertas $\mathrm{pH}$, spatula, pipet tetes, vakum epavorator, ayakan (nomor 40). Bahan yang digunakandalam penelitian ini yaitu: Daun sembung, etanol 96\%, paraffin, vaselin album, menthol, ceraalba, aquadest, asam sulfat pekat, kloroform, asam anhidrat asetat.

\section{Pembuatan Balsam}

Timbang semua bahan yang ada untuk membuat basis balsam bahan yang diperlukan ialah paraffin liquid,vaselinalbum, menthol, dan cera alba kemudian leburkan diatas penangasair,setelah semuabahansudah lebur, ekstrak daunkemangidihitung dantambahkan masing-masing ekstrakminyak atsiri daun sembung pada konsentrasi $10 \%(4 \mathrm{~mL}), 12 \%(4,8$ $\mathrm{mL})$, dan $14 \%$ (5,6 mL).kemudianaduksampai homogen dan biarkan hingga dingin dan masukkankedalamwadahyang sudah tersedia.

\section{Rancangan Formula}

Tabel 1. Formulasi balsam aromatherapy

\begin{tabular}{|c|c|c|c|c|}
\hline \multirow{2}{*}{ Bahan } & $\begin{array}{c}\text { Formulasi } \\
\text { dasar }\end{array}$ & \multicolumn{3}{|c|}{$\begin{array}{r}\text { Formulasi BalsamAromatherapy } \\
\text { Ekstrak Minyak Atsiri Daun } \\
\text { Sembung }\end{array}$} \\
\cline { 2 - 5 } & F I & F II & F III & F IV \\
\hline Ekstrak & - & $10 \%$ & $12 \%$ & $14 \%$ \\
\hline Paraffin. Liquid & $8 \mathrm{~g}$ & $8 \mathrm{~g}$ & $8 \mathrm{~g}$ & $8 \mathrm{~g}$ \\
\hline Mentol & $6 \mathrm{~g}$ & $6 \mathrm{~g}$ & $6 \mathrm{~g}$ & $6 \mathrm{~g}$ \\
\hline Cera Alba & $6 \mathrm{~g}$ & $6 \mathrm{~g}$ & $6 \mathrm{~g}$ & $6 \mathrm{~g}$ \\
\hline Vaselin Album & $20 \mathrm{~g}$ & $20 \mathrm{~g}$ & $20 \mathrm{~g}$ & $20 \mathrm{~g}$ \\
\hline
\end{tabular}

\section{HASIL DAN PEMBAHASAN}

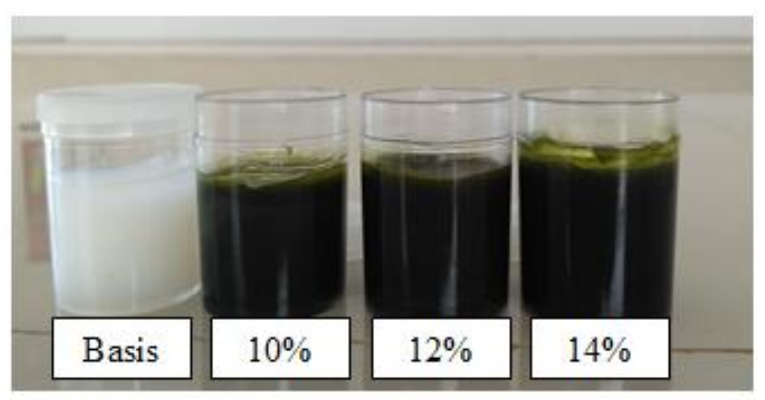

Gambar 1. Hasil Balsam Minyak Atsiri Daun Sembung 
Tabel 2. Komposisis Bahan Formula Balsam

\begin{tabular}{|c|c|c|c|c|}
\hline \multirow{2}{*}{ Bahan } & $\begin{array}{c}\text { Formulasi } \\
\text { dasar }\end{array}$ & \multicolumn{3}{|c|}{$\begin{array}{r}\text { Formulasi BalsamAromatherapy } \\
\text { Ekstrak Minyak Atsiri Daun } \\
\text { Sembung }\end{array}$} \\
\cline { 2 - 5 } & F I & F II & F III & F IV \\
\hline Ekstrak & - & $10 \%$ & $12 \%$ & $14 \%$ \\
\hline Paraffin. Liquid & $8 \mathrm{~g}$ & $8 \mathrm{~g}$ & $8 \mathrm{~g}$ & $8 \mathrm{~g}$ \\
\hline Mentol & $6 \mathrm{~g}$ & $6 \mathrm{~g}$ & $6 \mathrm{~g}$ & $6 \mathrm{~g}$ \\
\hline Cera Alba & $6 \mathrm{~g}$ & $6 \mathrm{~g}$ & $6 \mathrm{~g}$ & $6 \mathrm{~g}$ \\
\hline Vaselin Album & $20 \mathrm{~g}$ & $20 \mathrm{~g}$ & $20 \mathrm{~g}$ & $20 \mathrm{~g}$ \\
\hline
\end{tabular}

Tabel 3. Hasil Pengamatan OrganoleptisBalsam Minyak Atsiri Daun Sembung

\begin{tabular}{c|c|l|l}
\hline Formula & Warna & Tekstur & \multicolumn{1}{c}{ Aroma/Bau } \\
\hline I & Putih & Setengah padat & Menthol \\
II & Hijau Tua, kecoklatan & Setengah padat & Sembung, Kurang tajam \\
III & Hijau Tua, kecoklatan & Setengah padat & Sembung, Tajam (Khas) \\
IV & Hijau Tua, kehitaman & Setengah padat & Sembung, Tajam (Khas) \\
\hline
\end{tabular}

Tabel 4. Hasil Pengamatan Uji Homogenitas

\begin{tabular}{c|c|c}
\hline Formula & Warna & Homogenitas \\
\hline I & Putih & Homogen \\
II & Hijau Tua, kecoklatan & Homogen \\
III & Hijau Tua, kecoklatan & Homogen \\
IV & Hijau Tua, kehitaman & Homogen \\
\hline
\end{tabular}

Dalam penelitian ini telah dilakukan pengambilan ekstrak minyak atsiri dari daun sembung dengan menggunakan metode sokletasi, penelitian ini bertujuan untuk memanfaatkan daun sembung yang belum dimanfaatkan secara optimal. Pemilihan metode sokletasidikarenakan metode ini sangat cocok dalam megekstrak minyak atsiri, dikarenakan proses ektraksi yang kontinyu maka sampel terekstraksi oleh pelarut murni hasil kondensasi sehingga tidak membutuhkan banyak pelarut dan tidak memakan banyak waktu. Pengekstrakan ini dilakukan dengan menggunakan pelarut etanol 96\% kemudian dilakukan penguapan dalam alat sokletasi selama 2-8 jam. Hasil eksrtrak yang diperoleh kemudian dievaporasi untuk mendapatkan hasil minyak murni daun sembung. Minyak atsiri yang didapat kemudian digunakan sebagai bahan aromatherapy pada sediaan balsam dengan penambahan jumlah ekstrak yang berbeda pada 4 formula yang berbeda pada formula I yaitu basisibalsam tanpa penambhan ekstrak minyak atsiri daun sembung, pada formula II, III dan IV diberi tambahan minyak atsiri daun sembung dengan konsentrasi yang berbeda yaitu $10 \%$, 
$12 \%$ dan $14 \%$. Kemudian dilakukan uji kesukaan terhadap 10 orang responden hal ini bertujuan untuk mengetahui pada formula mana yang disukai oleh responden dengan uji kesukaan dengan memberi pendapat melalui nilai dalam bentuk angket persentase jawaban responden dapat dilihat pada Diagram batang dibawah ini.

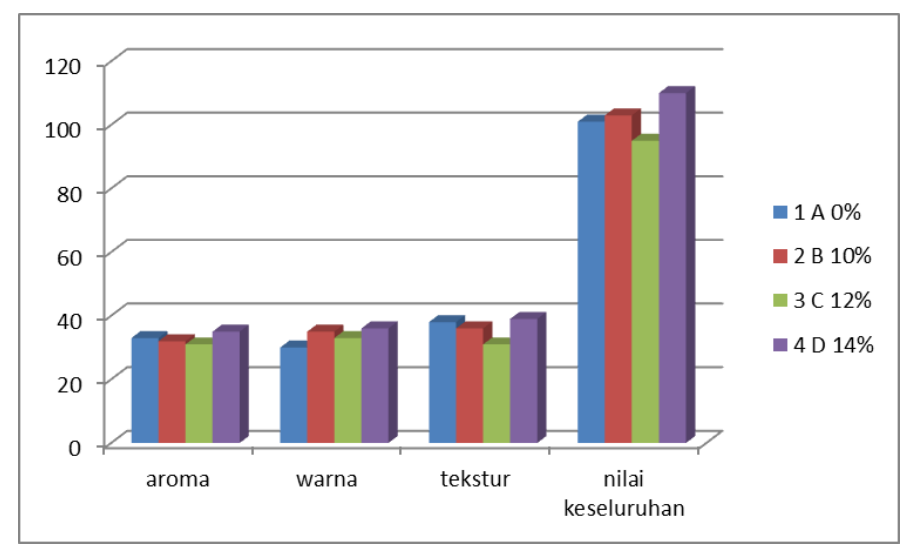

Gambar 2. Hasil analisa fitokimia minyak aromatherapy

Dari hasil yang diperoleh berdasarkan nilai yang diberikan oleh responden terhadap beberapa sampel balsam dengan tambahan minyak aromatherapy daun sembung yang beberbeda konsentrasi dan pemberian kode A $(0 \%), \mathrm{B}(10 \%), \mathrm{C}(12 \%)$ dan $\mathrm{D}(14 \%)$ terhadap sampel untuk memudahkan responden memberi penilaian terhadap balsam tersebut. Hasil perolehan nilai dengan persentase tertinggi terdapat pada balsam dengan kode sampel D yang memiliki konsentrasi 14\% dengan tambahan minyak daun sembung 5,6 mL, balsam dengan konsentrasi $14 \%$ lebih banyak disukai dikarenakan aroma daun sembung lebih tajam dibandingkan dengan konsentrasi $\mathrm{A}(0 \%), \mathrm{B}(10 \%)$ dan $\mathrm{C}(12 \%)$.

\section{KESIMPULAN}

Dari hasil penelitian yang dilakukan didapatkan kesimpulan sebagai berikut:

1. Daun sembung memiliki kandungan minyak atsiri yang dapat dijadikan aromatherapy alami pada sediaan balsam

2. Mengestrak minyak atsiri pada daun sembung dilakukan dengan menggunakan metode sokletasi dengan pelarut etanol 96\%, minyak atsiri yang diperoleh memiliki volume 15 mL. Minyak daun sembung yang dihasilkan berupa caira kental bewarna hijau kehitaman. 
3. Minyak atsiri daun sembung dapat digunakan sebagai aromatherapy pada sediaan balsam, balsam yang dihasilkan memenuhi syarat dan telah dilakukan evaluasi pada sediaan balsam, pada uji kesukaan aroma, tekstur, dan warna terhadap 10 orang responden diperoleh persentase tertinggi pada balsam minyak daun sembung dengan kode sampel D dan memiliki konsentrasi 14\% dengan tambahan 5,6 mL minyak daun sembung.

\section{SARAN}

Disarankan untuk peneliti selanjutnya meneliti Daun sembung dalam bentuk formulasi lainnya.

\section{DAFTAR PUSTAKA}

Pang Y., Wang D., Fan Z., Chen X., Yu F., Hu X. 2014. External Application of the Volatile Oil from Blumea balsamiferaMay Be Safe for Liver - A Study on Its Chemical Composition and Hepatotoxicity:Tropical Crops Genetic Resources Institute and Chinese Academy of Tropical Agricultural Sciences. ISSN 0255-2922.

Piliang L.K. 2011. Isolasi dan Analisis Komponen Kimia Minyak atsiri Daun Sembung (Blumea balsamifera) di Daerah Sunggal Kota Madya Medan GC-MS dan Uji Anti Bakteri. Tessis, Fakultas Matematika dan Ilmu Pengetahuan Alam, Universitas Sumatra Utara. Medan

Triratnawati A. 2010. Pengobatan Tradisional Upaya Meminimalkan Biaya Kesehatan Masyarakat Desa di Jawa. Jurnal penelitian. Jurusan Antropologi, Fakultas Ilmu Budaya, UGM, Yogyakarta

Zulkarnain I., dan Aminullah, 2012. Formulasi minyak-minyak menguap menjadi sediaan balsamCounterriritant. Jurnal penelitian. Makasar As-Syifaa Vol 04 (01) : Hal. 32-41, ISSN : 2085-4714 